\title{
Generation of high-titer of neutralizing polyclonal antibodies against heat-stable enterotoxin (STa) of enterotoxigenic Escherichia coli
}

\author{
Nasr-Eldin M. Aref ${ }^{*}$ and A. Mahdi Saeed \\ Department of Large Animal Clinical Sciences, College of Veterinary Medicine, Michigan State \\ University, East Lansing, MI 48823, USA
}

\begin{abstract}
In this study, polyclonal antibodies with high titer and avidity to native heat-stable enterotoxin (STa) of enterotoxigenic Escherichia coli (ETEC) have been generated and evaluated for their neutralizing effect in STa-induced enterotoxic animal model. Native STa was purified to homogeneity and coupled to modified bovine serum albumin (MBSA) using dimethylformamide (DMF)-based conjugation protocol. STa conjugate was used for immunization of female New Zealand white rabbits. The humoral immune response of the rabbits against native STa was monitored and evaluated for its antibody binding and neutralization capacity by ELISA and suckling mouse assay, respectively. After three subsequent boosts by STa conjugate, the animals were capable of eliciting high levels of STa-antibody binding titer $\left(10^{6}\right)$ and STa-neutralizing antibody capacity $\left(3 \times 10^{4}\right.$ mouse units of STa/ml serum). STa antibody maturation (avidity) was improved dramatically after multiple boosters with the STa conjugate. Comparison of the avidity of STa antibodies demonstrated that the strength in the STa antibody avidity developed in time corresponding to the development of the STa-neutralizing and binding titers. High avid STa antibodies ( $48.21 \%$ avidity index) were demonstrated 24 weeks post immunization (PI). However, differences in the onset of STa antibody production were noticed among animals and may need further investigation.
\end{abstract}

\section{Keywords}

Heat-stable enterotoxin; STa-conjugate; STa antibody response; STa antibody avidity

\section{Introduction}

Strains of enterotoxigenic Escherichia coli (ETEC) are a major cause of diarrheal disease among neonatal animals, children and travelers [1-3]. The antigenic diversity of these strains (enterotoxin/colonization factors [CFs] combinations) accounts for the high

\footnotetext{
(C) 2012 Elsevier Ltd. All rights reserved.

"Corresponding author. aref71@ hotmail.com (N.-E.M. Aref)..

Publisher's Disclaimer: This is a PDF file of an unedited manuscript that has been accepted for publication. As a service to our customers we are providing this early version of the manuscript. The manuscript will undergo copyediting, typesetting, and review of the resulting proof before it is published in its final citable form. Please note that during the production process errors may be discovered which could affect the content, and all legal disclaimers that apply to the journal pertain.

Current address: Department of Animal Medicine, Faculty of Veterinary Medicine, Assiut University, Assiut 71526, Egypt. Tel.: +20 088 2334699; fax: +20 0882232564 .

Conflict of interest

None of the authors have any conflict of interest to declare.
} 
prevalence of ETEC diarrhea in endemic areas [4]. Currently, there are no effective vaccines or immune-based therapies that confer a broad protection against the wide array of ETEC strains $[4,5]$. While targeting CFs antigen may help protect against some but not all ETEC strains, these CFs may undergo antigenic evolution causing failure of the currently used CFs-based ETEC vaccines [4]. On the other hand, targeting enterotoxins, heat-labile (LT) and heat-stable (ST), is rationalized by their conservative antigenic structure in all ETEC strains [5]. This strategy was successful to protect against LT because of its immunogenity which is similar to cholera toxin [6]. However, this approach has been challenged to protect against STa that presents in approximately $75 \%$ of all clinical ETEC isolates [7] partly because of its haptenic nature $(<2 \mathrm{kDa})$ [8]. Additionally, the correlation between STa toxicity and antigenicity $[9,10]$ hampers the ability to produce a safe STa-based ETEC vaccine. Several approaches have been explored to construct immunogenic STa molecules either via chemically coupling STa to various carrier proteins or genetically developing hybrid STa fusion proteins [11-26]. In general, these constructions failed to elicit optimal STa-neutralizing antibodies [10]. Possibly reason is due to inefficient presentation of STa epitops on the carrier protein. However, hapten-carrier conjugation protocols are still a primary choice for constructing immunogen because of its simplicity and effectiveness in induction of both humoral and cell-mediated immune responses [27,28]. The carrier molecule provides the T-cell antigenic determinants for T-cell signaling, proliferation and release of mediators which activate specific B cells to stimulate antibody production against both hapten and carrier [29]. The critical point in these protocols is to understand the molecular structure of the hapten and preserve its antigenic determinants during the conjugation process. The present study was carried out to characterize the humoral immune response against a well-defined STa conjugate. The antibody response against native STa was monitored during immunization process by specific ELISA binding, avidity and neutralization capacities.

\section{Materials and methods}

\subsection{Reagents}

All reagents were obtained from commercial sources and were of analytical grade (Sigma Chemical Company, St. Louis, Mo, USA).

\subsection{Animals}

Ten 8-weeks old female New-Zealand albino rabbits were obtained from Charles River Laboratories (Wilmington, MA) and housed in approved-size single cages at the Containment Facility of Michigan State University, USA. Temperature and humidity were kept at $20 \pm 4{ }^{\circ} \mathrm{C}$ and $55 \%$, respectively. Rabbits were checked on a daily basis for their health status by qualified staff and veterinarians. Animal studies were approved by the Michigan State University Institutional Animal Care and Use Committee (MSU-IACUC) and were performed in compliance with institutional guidelines.

\subsection{Construction of STa immunogen using specific hapten-carrier conjugation protocol}

STa immunogen was prepared according to Aref and Saeed [30]. Briefly, STa conjugate was constructed in four different steps: (1) modification of bovine serum albumin (MBSA) by introducing carboxyl moieties in known succinylation reaction [31] (2) activation of the $M B S A$ by incubation of the MBSA with $p$-nitrophenol and $N, N$-dicyclohexylcarbodiimide in DMF solvent medium (3) covalently cross-linking STa to the MBSA: native STa peptide in DMF was added to the activated MBSA followed directly by triethylamine and stirred overnight at room temperature (4) finally, dilution and dialysis: three volumes of Milli Q water were added and the mixture was extensively dialyzed (M.W. cutoff 12-14 kDa) and then lyophilized. The STa conjugate was tested for its biological activity and structural 
identity by suckling mouse assay (SMA) [32] and matrix-assisted laser desorption ionization-time of flight/mass spectroscopy (MALDI-TOF/MS), respectively.

\subsection{Immunization}

Standard operating procedures for handling and immunization of rabbits in compliance with the guidelines and recommendations of MSU-IACUC were adopted. Briefly, a water-in-oil emulsion of STa conjugate in Freund's adjuvant was prepared as following: $20 \mathrm{mg}$ of lyophilized STa conjugate were reconstituted in $10 \mathrm{ml} 0.01 \mathrm{M}$ PBS [pH 7.0] and added to 10 $\mathrm{ml}$ of Freund's complete adjuvant. The mixture was homogenized by polytron at $15,000 \mathrm{rpm}$ for $10 \mathrm{~min}$ or until stable water-in-oil emulsion was obtained. The 10 rabbits were then inoculated intradermally by $0.5 \mathrm{ml}$ of the emulsion at multiple sites [33] (primary immunization). Each rabbit was then similarly inoculated by $0.5 \mathrm{ml}$ of STa conjugate mixed with Freund's incomplete adjuvant at three-week intervals (boosting immunization) until STa-neutralizing antibodies were detected.

\subsection{Animal bleeding}

Blood samples from all rabbits were collected from the central ear artery [34] after one week of adaptation and before immunization program to obtain a reference baseline for serum titers. Blood samples were then collected after three weeks of primary immunization and then weekly after boosting immunization. After collection using serum separator BD vacutainer tubes, blood was allowed to clot for $30 \mathrm{~min}$ at $37^{\circ} \mathrm{C}$. The clot was then separated from the sides of the tubes and allowed to contract at $4{ }^{\circ} \mathrm{C}$ overnight. The separated sera were collected by centrifugation at $2000 \mathrm{rpm}$ for $30 \mathrm{~min}$, aliquot and kept at $20^{\circ} \mathrm{C}$. The sera were tested for neutralization, binding capacity and affinity/avidity assays against native STa using SMA, indirect ELISA binding and ELISA avidity assay, respectively.

\subsection{Neutralization of STa enterotoxicity}

A modified protocol of SMA [19] was adopted to determine the STa-antibody neutralization capacity. Neutralization capacity is defined as the total mouse units (MUs) of STa that were neutralized per one ml serum. Neutralization specific activity is defined as the total MUs of STa that were neutralized per one mg serum protein.

\subsection{Kinetics of STa-humoral immune response}

\subsubsection{Indirect ELISA for detecting and monitoring STa antibody titer-An} indirect binding ELISA in which STa antigen was bound to a solid phase and reaction with antibody-containing samples was allowed in order to detect and monitor the presence of STa antibodies in rabbit sera [35]. STa antibody titers were obtained from the serum dilution curves prepared for the ELISA and expressed as the reciprocal of the serum dilution giving an absorbance reading at $405 \mathrm{~nm}\left(\mathrm{Abs}_{405}\right)$ greater than the mean of $\mathrm{Abs}_{405}$ of baseline sera plus two standard deviations ( $X_{\mathrm{Abs} 405}$ baseline $\left.+2 \mathrm{SD}\right)$.

2.7.2. Avidity ELISA-Avidity (functional affinity) is the measure of the overall strength of binding of an antigen with many antigenic determinants and multivalent antibodies [36]. In this study, the STa-antibody avidity was measured by comparing the amount of antibodies that could bind the STa antigen in absence and presence of a chaotropic agent. In this test, a chaotropic agent, ammonium thiocyanate (AT), was added in increasing molar concentrations to the tested sera-STa complex. Low avid STa antibodies in the tested sera were dissociated from this complex at low molar concentrations of AT. The procedure was performed in a similar fashion of indirect ELISA binding protocol with the inclusion of one additional step in which, after incubation of tested sera with STa antigen, plates were washed and blotted four times and $100 \mu \mathrm{l}$ of three different molar concentrations $(1.25,2.5$ 
and $5 \mathrm{M}$ ) of AT in PBS were added to each well in duplicates and incubated at $37^{\circ} \mathrm{C}$ for 15 min. Plates were then processed as indirect ELISA binding assay. Avidity index (AI) percent was calculated as following:

$$
\mathrm{AI}(\%)=\frac{\text { Mean OD of AT treated wells } \times 100}{\text { Mean OD of untreated wells }}
$$

\subsection{Statistical analysis}

Generated data of binding and avidity ELISA as well as neutralization capacity were subjected to statistical analysis using SPSS (1999) program for windows version 10.0.1 (SPSS Inc., Chicago, IL) for calculation of mean and standard deviation.

\section{Results}

\subsection{Construction of STa immunogen}

STa peptide was successfully conjugated to the MBSA. Results of this procedure were presented in (Table 1, Fig. 1).

\subsection{Neutralization of STa enterotoxicity}

Sera from immunized rabbits were tested for STa-antibody neutralization capacity by modified SMA. Eighty \% of rabbits elicited STa-neutralizing antibody and their sera protected STa-challenged suckling mice (SMA $=0.06 \pm 0.001$ ), however their onset of STa antibody production were different. Three rabbits (group 1) showed STa-neutralizing antibody at 12th week PI with neutralization capacity of $3 \times 10^{4} \mathrm{MUs}$ of STa $/ \mathrm{ml}$ serum. Another three rabbits (group 2) showed the same STa-antibody neutralization capacity however their antibody response was detected at 17th week PI. Finally two rabbits (group 3) showed relatively low antibody response 20th week PI. Fig. 2 shows STa-antibody neutralization using SMA cutoff value 0.083 .

\subsection{Kinetics of STa-humoral immune response}

\subsubsection{STa antibody binding assay}

3.3.1.1. ELISA optimization: ELISA protocol was optimized after testing various serum dilutions $\left(10^{-3}, 10^{-4}, 10^{-5}\right.$ and $\left.10^{-6}\right)$ from immunized rabbits. Dilution of $10^{-4}$ was recognized as the equivalence point of antigen-antibody interaction (Fig. 3). This dilution was used in assessment of the titer and avidity index of the anti-STa antibody by the indirect and avidity ELISA.

3.3.1.2. STa-ELISA findings: STa antibody binding on $10^{-4}$ dilution of tested serum showed slight binding titers after 6 weeks of immunization in group 1, 2 and $3(\mathrm{OD}=1.092$ $\pm 0.46,0.567 \pm 0.39$ and $0.671 \pm 0.23$, respectively), however no detectable STaneutralizing antibody at this stage. By 12 weeks PI, group 1 was able to demonstrate high STa-antibody binding titer $\left(10^{6}\right.$, mean $\left.\mathrm{OD}=2.178 \pm 0.059\right)$ corresponding to presence of STa-neutralizing antibody. While rabbits in group 2 showed relatively late onset of STaneutralizing antibody (17 weeks PI), the same binding titer $\left(10^{6}\right.$, mean OD $\left.=1.986 \pm 0.093\right)$ was also obtained. Both group 1 and 2 demonstrated high STa-antibody neutralization capacity $\left(3 \times 10^{4} \mathrm{MU} / \mathrm{ml}\right.$ serum $)$ corresponding to high STa antibody binding titer but at different time. On the other hand, group 3 mounted relatively lower STa antibody binding titer $\left(10^{4}, \mathrm{OD}=1.381 \pm 0.394\right)$ corresponding to STa-neutralizing antibodies by 20 th week PI. Fig. 4 shows mean OD value of group 1, 2 and 3 rabbits over the period immunization. Maximum OD value of STa antibody binding were 2.268 $\pm 0.124,2.067 \pm 0.070$ and 1.656 
\pm 0.035 at 20,20, and 24 weeks PI in group 1, 2 and 3, respectively. Fig. 5 showed the pattern of STa-specific serum antibody end titer after 24 weeks PI at various serum dilutions. Summary of STa binding and neutralization end titers were presented in Table 2.

3.3.2. STa antibody avidity-Our data showed that the maturation of humoral response to STa peptide is variable over the time of immunization period. The increasing molar concentration of AT, from 1.25 and 2.5 to $5 \mathrm{M}$, was needed to dissociate STa-antibody complex. The first two molar concentrations of AT showed no significant STa antigenantibody complex dissociation. The time course evaluation of STa antibody avidity using AT (5 M) dose response was depicted in Fig. 6. Toward the end of immunization experiment (24th week PI), sera from groups 1, 2 and 3 demonstrated variable AI $(48.21 \%, 38.71 \%$ and $21.30 \%$, respectively).

\section{Discussion}

Since STa is a small molecule, it is not naturally immunogenic. In order to produce specific antibody to STa, a conjugate was constructed and used as immunogen for immunization of animals. To monitor the progress of the immune response, serum samples were collected weekly after each booster immunization and analyzed by indirect ELISA and SMA to assess its binding and neutralizing titers, respectively.

The present study showed that polyclonal antibodies with high avidity to native STa could be generated. Both high STa antibody binding (indicated by the absorbance values) and neutralizing (indicated by the total neutralized MUs) titers were obtained. However variations in the onset of humoral response were noticed. Sixty \% of animals (group $1 \& 2$ ) elicited high STa-neutralizing antibody with high binding titer at 12 and 17 weeks of immunization while group 3 showed weaker STa-neutralizing antibody at 20 weeks of immunization. Furthermore, data of STa antibody avidity showed that the maturation of humoral response to native STa peptide was variable but consistent with the data of STa antibody binding and neutralizing titers among these animals. Measurement of STa antibodies avidity using AT at several increasing molar concentrations suggested that the avidity of STa antibodies improved dramatically after multiple boosters with the STaconjugate. Comparison of the avidity of STa antibodies demonstrated that the strength in the STa antibody avidity developed in time corresponding to the development of the STaneutralizing and binding titers of the tested sera. These variations in the patterns of dissociation of the STa antibodies could be fundamentally attributed to the process of clonal selection and antibodies maturation after immunization and continuous boosting protocols [37] yet, it is not fully understood why some rabbits behaved differently in the onset of their immune response against STa immunogen. The variation might be explained by the lack of intimate connection between the immunologically competent areas of the late and/or poorly responded animals and the STa antigenic determinants. This difference in antibody response is in general agreement with the theory of Dineen [38] which stated that the threshold level of antigen for antibody stimulation depended on the antigenic disparity between the individual host and the immunogen and the rate of flow of antigenic information from the immunogen to the reticulo-endothelial system of the host. In the present case, continued stimulation of the animals might have improved this connection and the efficiency of the circulating antibody in the neutralization of this low-molecular-weight toxin towards the end of the experiment. Thus far, such variations may worth additional investigation in the future studies. In vitro kinetic studies of this immunogen would be helpful in understanding this variation. Additionally, studying the antigen-binding site on the hypervariable region of the anti-STa IgG from group 1 animals would be of great help in designing an effective and reliable immunotherapeutic reagent against STa. 


\section{Conclusions}

The present study described the generation and preliminary characterization of neutralizing antibodies to STa. These antibodies showed high binding titer and recognized STa with high avidity. However, differences in the onset of antibody production were noticed among animals and may need further investigation. The results of this study might propose the potential use of this immunogen for development of a reliable serological test or constructing an ST-toxoid ETEC vaccine.

\section{Acknowledgments}

This project was supported by the National Institute of Health, USA. We gratefully acknowledge Ronald Erskine Ph. D. and Daniel Grooms Ph. D., Department of Large Animal Clinical Sciences, Robert Roth Ph. D. and Particia Ganey Ph. D., Department of Pharmacology and Toxicology, Michigan State University, East Lansing, MI, USA.

\section{References}

1. Gyles, CL. Escherichia coli in Domestic Animals and Humans. 1st ed.. CAB International; Wallingford, UK: 1996. p. 31-72.

2. Kosek M, Bern C, Guerrant RL. The magnitude of global burden of diarrhoeal disease from studies published 1992-2000. Bulletin of the World Health Organization. 2003; 81:197-204. [PubMed: 12764516]

3. Svennerholm A-M, Steele D. Progress in enteric vaccine development. Best Practice and Research Clinical Gastroenterology. 2004; 18:421-445. [PubMed: 15123079]

4. Walker RI, Steele D, Aguado T. Ad Hoc ETEC, Technical Expert Committee. Analysis of strategies to successfully vaccinate infants in developing countries against ETEC disease. Vaccine. 2007; 25:2545-2566. [PubMed: 17224212]

5. Boedeker EC. Vaccines for enterotoxigenic Escherichia coli: current status. Current Opinion in Gastroenterology. 2005; 21:15-19. [PubMed: 15687879]

6. Svennerholm A-M, Tobias J. Vaccines against enterotoxigenic Escherichia coli. Expert Review of Vaccines. 2008; 7:795-804. [PubMed: 18665777]

7. Taxt A, Aasland R, Sommerfelt H, Nataro J, Puntervoll P. Heat-stable enterotoxin of enterotoxigenic Escherichia coli as a vaccine target. Infection and Immunity. 2010; 78:1824-1831. [PubMed: 20231404]

8. Pereira CM, Guth BE, Sbrogio-Almeida ME, Castilho BA. Antibody response against Escherichia coli heat-stable enterotoxin expressed as fusions to flagellin. Microbiology. 2001; 147:861-867. [PubMed: 11283282]

9. Takeda T, Nair GB, Suzuki K, Zhe HX, Yokoo Y, Hemelhof W, Butzler JB, Takeda Y, Shimonishi Y. Epitope mapping and characterization of antigenic determinants of heat-stable enterotoxin (STh) of enterotoxigenic Escherichia coli by using monoclonal antibodies. Infection and Immunity. 1993; 61:289-294. [PubMed: 7678100]

10. Ruth N, Mainil J, Roupie V, Frere J-M, Galleni M, Huygen K. DNA vaccination for the priming of neutralizing antibodies against non immunogenic STa enterotoxin from enterotoxigenic Escherichia coli. Vaccine. 2005; 23:3618-3627. [PubMed: 15855022]

11. Frantz JC, Robertson DC. Immunological properties of Escherichia coli heat-stable enterotoxins: development of a radioimmunoassay specific for heat-stable enterotoxins with suckling mouse activity. Infection and Immunity. 1981; 33:193-198. [PubMed: 6167519]

12. Klipstein FA, Engert RF, Clements JD, Houghten RA. Vaccine for enterotoxigenic Escherichia coli based on synthetic heat-stable toxin crossed linked to the B subunit of heat-labile toxin. Journal of Infectious Diseases. 1983; 147:318-326. [PubMed: 6338132]

13. Klipstein FA, Engert RF, Houghten RA. Properties of cross-linked toxoid vaccines made with hyperantigenic forms of synthetic Escherichia coli heat-stable toxin. Infection and Immunity. 1984; 44:268-273. [PubMed: 6425218] 
14. Lockwood DE, Robertson DC. Development of a competitive enzyme-linked immunosorobent assay (ELISA) for Escherichia coli heat-stable enterotoxin (STa). Journal of Immunological Methods. 1984; 75:295-307. [PubMed: 6520401]

15. Houghten RA, Ostresh JM, Klipstein FA. Chemical synthesis of an octadecapeptide with the biological and immunological properties of human heat-stable Escherichia coli enterotoxin. European Journal of Biochemistry. 1984; 145:157-162. [PubMed: 6386477]

16. Houghten RA, Engert RF, Ostresh JM, Hoffman SR, Klipstein FA. A completely synthetic toxoid vaccine containing Escherichia coli heat-stable toxin and antigenic determinants of the heat-labile toxin B subunit. Infection and Immunity. 1985; 48:735-740. [PubMed: 2581899]

17. Sanchez J, Uhlin BE, Grundstrom T, Holmgren J, Hirst TR. Immunoactive chimeric ST-LT enterotoxins of Escherichia coli generated by in vitro gene fusion. FEBS Letters. 1986; 208:194198. [PubMed: 2430831]

18. Svennerholm A-M, Wikstrom M, Lindblad M, Holmgren J. Monoclonal antibodies against Escherichia coli heat-stable toxin (STa) and their use in a diagnostic ST ganglioside GM1enzyme-linked immunosorbent assay. Journal of Clinical Microbiology. 1986; 24:585-590. [PubMed: 2429984]

19. Frantz JC, Bhatnagar PK, Brown AL, Garret LK, Hughes JL. Investigation of synthetic Escherichia coli heat-stable enterotoxin as an immunogen for swine and cattle. Infection and Immunity. 1987; 55:1077-1084. [PubMed: 3552985]

20. Sanchez J, Svennerholm A-M, Holmgren J. Genetic fusion of a nontoxic heat stable enterotoxinrelated decapeptide antigen to cholera toxin B-subunit. FEBS Letters. 1988; 241:110-114. [PubMed: 3058509]

21. Saarilahti HT, Palva ET, Holmgren J, Sanchez J. Fusion of genes encoding Escherichia coli heatstable enterotoxin and outer membrane protein OmpC. Infection and Immunity. 1989; 57:36633665. [PubMed: 2680976]

22. Löwenadler B, Lake M, Elmblad A, Holmgren E, Holmgren J, Karlström A, Svennerholm A-M. A recombinant Escherichia coli heat-stable enterotoxin (STa) fusion protein eliciting anti-STa neutralizing antibodies. FEMS Microbiology Letters. 1991; 82:271-278.

23. Aitken R, Hirst TR. Recombinant enterotoxins as vaccines against Escherichia coli-mediated diarrhoea. Vaccine. 1993; 11:227-233. [PubMed: 8438620]

24. Cárdenas L, Clements JD. Development of mucosal protection against the heat-stable enterotoxin (ST) of Escherichia coli by oral immunization with a genetic fusion delivered by a bacterial vector. Infection and Immunity. 1993; 61:4629-4636. [PubMed: 8406860]

25. Sanchez J, Argotte R, Buelna A. Engineering of cholera toxin A-subunit for carriage of epitopes at its amino end. FEBS Letters. 1997; 401:95-97. [PubMed: 9003813]

26. Batisson I, Der Vartanian M. Contribution of defined amino acid residues to the immunogenicity of recombinant Escherichia coli heat-stable enterotoxin fusion proteins. FEMS Microbiology Letters. 2000; 192:223-229. [PubMed: 11064199]

27. Elanger BF. The preparation of antigenic-hapten-carrier conjugates: a survey. Methods in Enzymology. 1980; 70 (A):85-104. [PubMed: 7421602]

28. Hermanson, GT. Bioconjugate Techniques. 2nd ed.. Elsevier Academic Press; San diego, Ca, USA: 2008.

29. De Silva BS, Egodage KL, Wilson GS. Purified protein derivatives (PPD) as an immunogen carrier elicits high antigen specificity to haptens. Bioconjugate Chemistry. 1999; 10:496-501. [PubMed: 10346883]

30. Aref N-EM, Saeed AM. Design and characterization of highly immunogenic heat-stable enterotoxin of enterotoxigenic Escherichia coli K99+ Journal of Immunological Methods. 2011; 366:100-105. [PubMed: 21277302]

31. Habeeb AF. Quantitation of conformational changes or chemical modification of proteins: Use of succinylated proteins as a model. Archives of Biochemistry and Biophysics. 1967; 121:652-664. [PubMed: 4169580]

32. Giannella R. Suckling mouse model for detection of heat-stable Escherichia coli enterotoxin: characteristics of the model. Infection and Immunity. 1976; 14:95-99. [PubMed: 780280] 
33. Vaitukaitis JL. Production of antisera with small doses of immunogen: multiple intradermal injections. Methods in Enzymology. 1981; 73:46-52. [PubMed: 7300686]

34. Gordon LK. A reliable method for repetitively bleeding rabbits from the central artery of the ear. Journal of Immunological Methods. 1981; 44:241-246. [PubMed: 7024418]

35. Lefkovits, I. Immunology methods manual. Vol. 4. Academic Press, Harcout Brace and Company, Publishers; San Diego, London, Boston, New York, Sydney, Tokyo, Toronto: 1997.

36. Ferreira MU, Katzin AM. The assessment of antibody distribution by thiocyanate elution: a simple dose-response approach. Journal of Immunological Methods. 1995; 187:297-305. [PubMed: 7499889]

37. Goldblatt, D. eLS. John Wiley \& Sons Ltd.; Chichester, UK: 2001. Affinity of Antigen-Antibody Interactions.; p. 1-5.

38. Dineen JK. Immunological aspects of parasitism. Nature (London). 1963; 197:268. [PubMed: 14027954]

39. Lateef SS, Gupta S, Jayathilaka LP, Krishnanchettiar S, Huang J-S, Lee B-S. An improved protocol for coupling synthetic peptides to carrier proteins for antibody production using DMF to solubilize peptides. Journal of Biomolecular Techniques. 2007; 18:173-176. [PubMed: 17595313] 


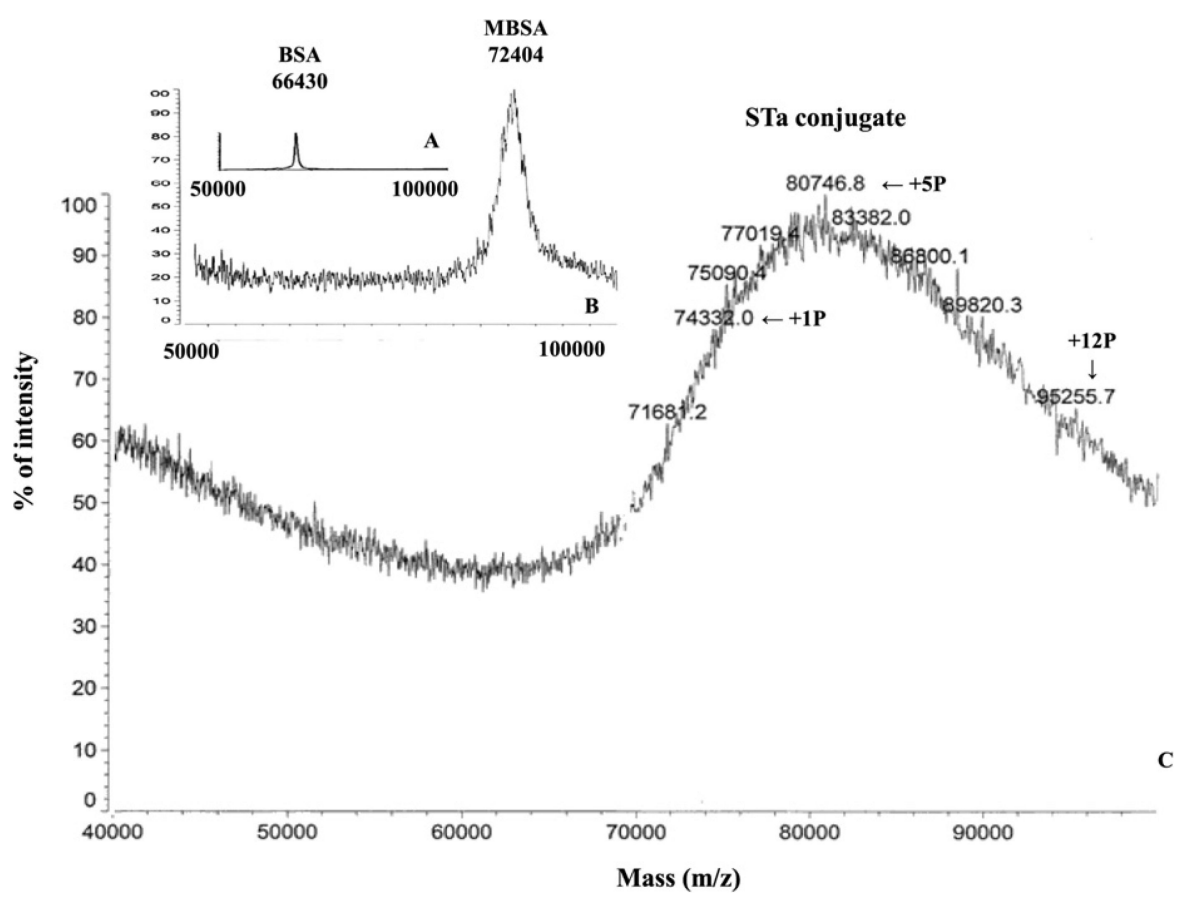

Fig. 1.

MALDI-TOF mass spectra of: (A) BSA (after Lateef et al. [39]); (B) MBSA; (C) MBSA + STa Peptide. In this figure, $+1 \mathrm{P}$ to $+12 \mathrm{P}$ stands for +1 peptide to +12 peptides, respectively. 


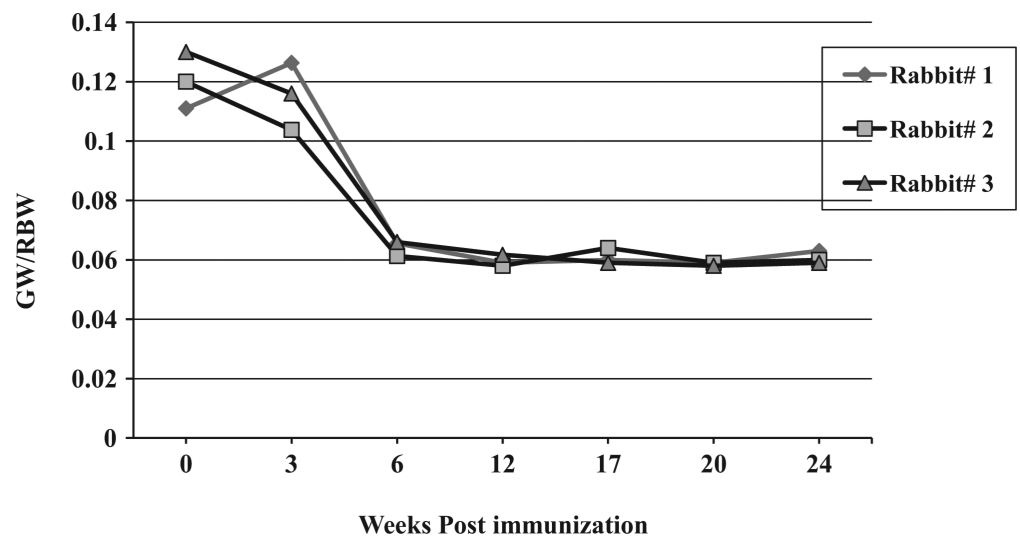

Fig. 2.

Time-course evaluation of STa antibody neutralization bioassay: cutoff value of SMA = 0.083, gut weight to remaining body weight ratio (GW/RBW). 


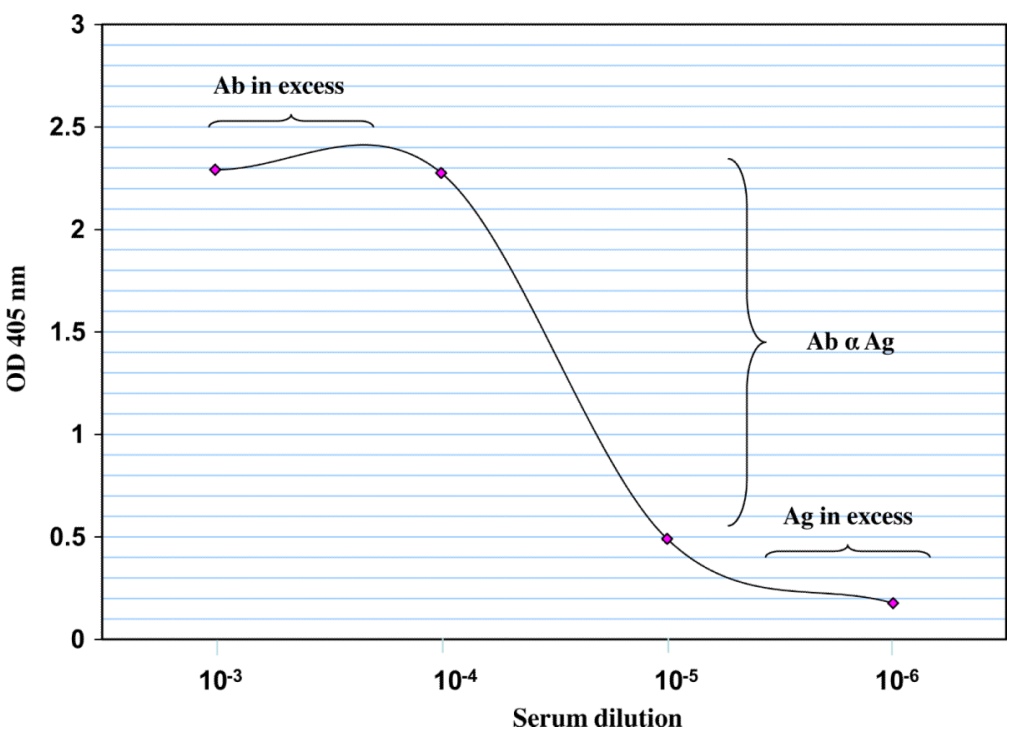

Fig. 3.

Determination of the proper dilution for STa-STa antibody interaction. 


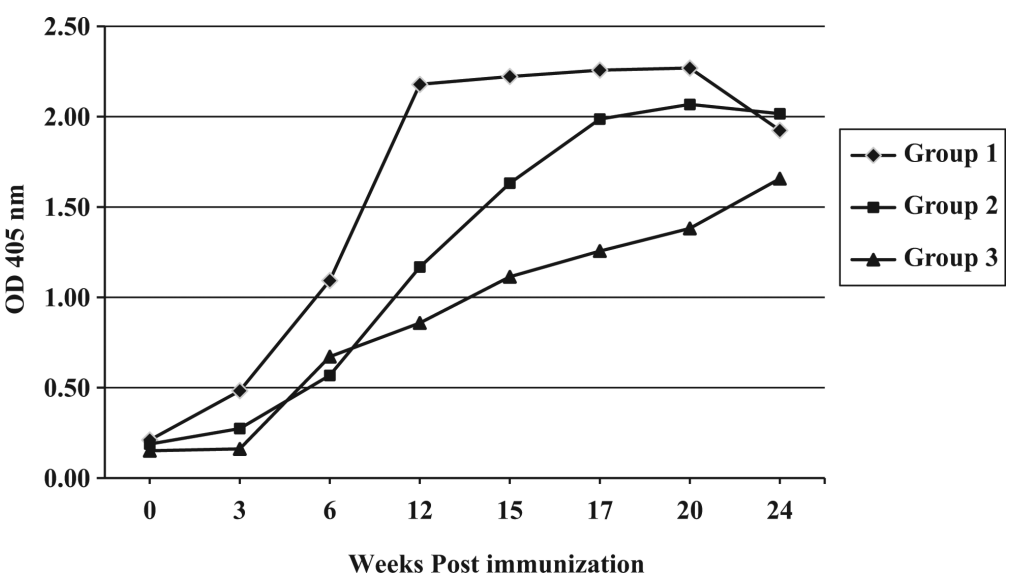

Fig. 4.

Time-course evaluation of STa antibody binding assay: mean OD value of group 1, 2 and 3 rabbits over the period of immunization at $10^{-4}$ serum dilutions. 


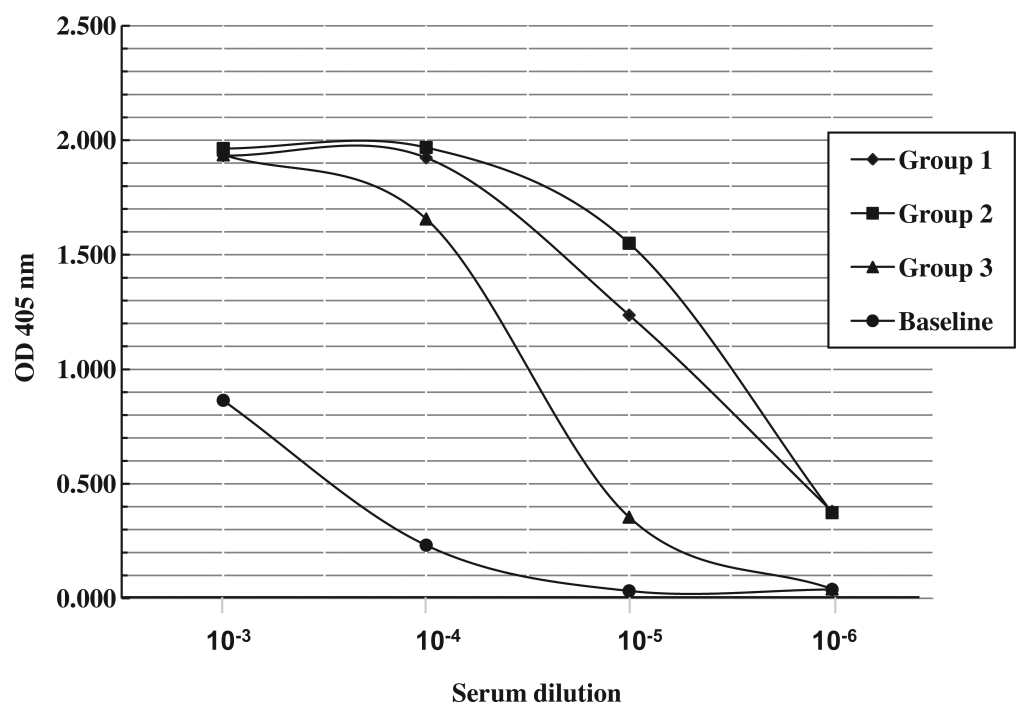

Fig. 5.

STa antibody binding end titer: mean OD value of group 1, 2 and 3 rabbits after 24 weeks of immunization at various serum dilutions. 


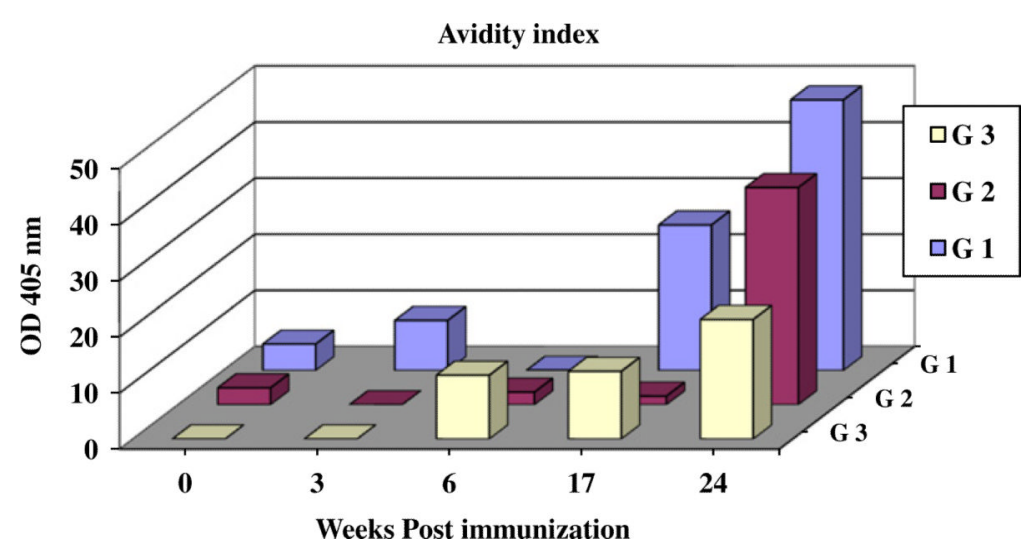

Fig. 6.

Avidity index of STa antibodies from group 1, 2 and 3 rabbits. 


\section{Table 1}

Results of constructing STa peptide-carrier conjugate.

\begin{tabular}{ll}
\hline Modification process of BSA & \\
MW of Native BSA according to Lateef et al. [39] & $66.430 \mathrm{kDa}$ \\
MW of MBSA based on MALDI-TOF/MS & $72.404 \mathrm{kDa}$ \\
$\begin{array}{l}\text { Composite after loading STa and extensive dialysis } \\
\text { Protein concentration }\end{array}$ & $1.96 \mathrm{mg} / \mathrm{ml}$ \\
Biological activity expressed as total MUs & $10^{7} \mathrm{MUs}$ \\
STa conjugate & \\
$\begin{array}{l}\text { 1. MW based on MALDI-TOF/MS } \\
\text { 2. Conjugation competence based on: }\end{array}$ & $80.746 \mathrm{kDa}$ \\
Protein concentration & $\sim 52-64 \%$ \\
Retained biological activity in STa conjugate & $100 \%$ \\
STa: MBSA conjugation ratio & $1-12: 1$ \\
\hline
\end{tabular}

Vaccine. Author manuscript; available in PMC 2013 October 05. 


\section{Table 2}

STa-binding and neutralization titers of rabbit sera immunized with STa-conjugate after the primary and boosting immunization. Data were generated by STa binding ELISA and STa neutralization suckling mouse assay.

\begin{tabular}{lrlll}
\hline Bleeding & Anti-STa response & Protein assay $(\mathbf{m g} / \mathbf{m l})$ & Neutralization specific activity \\
\cline { 2 - 4 } & ELISA binding titer & Neutralized STa MUs/ml serum & & \\
\hline Baseline & 0 & 0 & 64.5 & - \\
Week 3 PI & 0 & 0 & 66.8 & - \\
Week 6 PI & $\mathrm{ns}$ & 0 & 65.7 & - \\
Week 12 PI & $10^{6}$ & $2 \times 10^{3}$ & 83.5 & 23.95 \\
Week 15 PI & $10^{6}$ & $15 \times 10^{3}$ & 69.6 & 215.52 \\
Week 20 PI & $10^{6}$ & $2 \times 10^{4}$ & 65.00 & 307.69 \\
Week 24-28 PI & $10^{6}$ & $3 \times 10^{4}$ & 65.00 & 461.54 \\
\hline
\end{tabular}

ns, not significant. 